\title{
Efficacy of $e$-BPS: An adaptation of the Best possible Self exercise implemented through positive technology. A Randomized Control Trial
}

\begin{abstract}
Context Best possible Self (BPS) is a positive psychological intervention based on positive future thinking. It has been shown to be effective in improving well-being and depressive symptoms over short periods of time. Positive technology is a scientific approach designed to increase well-being through Information and Communication Technologies.
\end{abstract}

Objective To assess the efficacy of the BPS implemented through a positive technology application in improving optimistic thinking, affect and depressive symptoms, during a one-month period, with two follow-ups one and three months later.

Design, setting and participants Randomized, single-blind control trial. Central randomization was performed by an independent researcher using computer software to generate lists allocating participants to treatments. Recruitment was carried out through advertisements at two universities. Randomized participants were 78 young adults who were assigned to the e-BPS condition $(n=38)$ or to a control group $(n=40)$.

Interventions Participants were asked to visualize their BPS each day using a Positive Technology Application. The Control condition consisted of thinking and writing about daily activities, also through technologies.

Main outcome measures Affect, future expectations, and depressive symptoms were measured in different time frames.

Results 78 participants were analyzed using intention-to-treat analyses. Results showed that BPS was effective in improving future expectations measures and reducing depressive symptoms until the post-training. However, these effects were not maintained in the three-month follow-up period.

Conclusion This study indicates that BPS can also be effectively adapted for implementation through positive technologies. Factors such as the variety of exercises and the instructions can play a role in maintaining the changes in the long term.

Trial registration clinicaltrails.gov Identifier: NCT02321605

Funding Jaume I University grant PREDOC/2012/51

\section{Key Words}

Best Possible Self, future thinking, Positive Psychological Intervention, Positive Technology, Optimism, well-being 


\section{INTRODUCTION}

In the past fifteen years, the goal of positive psychology interventions has been to find out how to enhance and sustain the emergence of positive emotions and well-being. Meta-analyses have shown that these interventions are effective in improving wellbeing and depressive symptoms in the general population and in individuals suffering from specific psychosocial problems (Bolier et al. 2013; Sin \& Lyubomirsky, 2009).

One of these interventions is the Best Possible Self (BPS), proposed by King (2001) as a disclosure writing exercise where participants have to write about their life goals. In this activity, participants are asked to imagine and write an essay about themselves in the future, after everything has turned out as well as it possibly could, and read it every day during the established period (King, 2001; Sheldon \& Lyubomirsky, 2006). Results of King's studies showed that it was less upsetting and distressing than writing about other topics (i.e. writing about trauma), and it was even associated with decreased illness symptoms compared to controls (King, 2001; King \& Raspin, 2004). In this regard, given that depressive patients usually have a pessimistic view of their personal future (Rief et al., 2015), BPS has been shown effective in improving depressive symptoms in depressive and pessimistic individuals (Pietrowsky \& Mikutta, 2012; Sergeant \& Mongrain, 2014). It is important to note that, although these studies also collected information about positive variables, BPS was first designed to reduce negative symptoms and decrease illness (King, 2001).

The first study that included BPS as a Positive Psychological Intervention (PPI) to promote well-being was conducted by Sheldon and Lyubomirsky (2006). In this study, it was compared the efficacy of two PPIs: BPS and Expressing Gratitude, as a way to increase and sustain positive emotions, compared to a control condition. Furthermore, it was explicitly asked to the participants not only to write the essay, but also to visualize their best possible future. Results showed that, after 4 weeks, participants who performed one of the two PPIs increased their levels of positive affect significantly more than the control condition, but the effect was more pronounced in individuals who performed the BPS exercise. In addition, the BPS intervention has shown efficacy in improving positive affect and subjective well-being measures 6 and 8 weeks later (Boehm, Lyubomirsky \& Sheldon, 2011; Layous, Nelson \& Lyubomirsky, 2012; Lyubomirsky, Dickerhoof, Boehm \& Sheldon, 2011), but these effects were not maintained after 6 months (Lyubomirsky et al. 2011).

Although prior studies indicate that BPS is effective in improving some aspects of subjective well-being, these studies do not explore its effect on other variables. In this regard, it has been suggested that BPS, which is a future-oriented exercise, might have the potential to improve variables such as optimism and future expectations (Peters, Flink, Boersma \& Linton, 2010). In this sense, Peters and colleagues (2010) showed that the performance of the exercise was able to produce significant changes in future expectations in a single session, compared to a control condition (Peters et al. 2010). In another study, the BPS exercise was tested during a two-week period, producing 
improvements in dispositional optimism and future expectations compared to a control group (Meevissen, Peters and Alberts, 2011). In addition, Meevissen and colleagues (2011) provided specific domains for the imagery content (personal, professional, and social domains) in order to standardize the content of the exercise as much as possible. Furthermore, in a quite similar study, it was shown not only that the BPS exercise was able to produce changes in optimistic attributions and dispositional optimism after a week, but also its differential efficacy with a gratitude intervention, which is more focused on the past (Peters, Meevissen \& Hansen, 2013). However, there are no data about the maintenance of the effects on these specific variables related to the future beyond two weeks of intervention. The present study is aimed to cover this gap by analyzing the impact of an adaptation of BPS exercise on future expectations and optimism after one month of practice.

On the other hand, an important aspect of the BPS intervention is the way it is implemented. Up until now, the BPS exercise has been performed by writing on a blank sheet of paper. Thus, previous studies asked participants to write an essay about their best possible self and read it every day during the established period (King, 2001; Peters, et al. 2013). However, the use of Information and Communication Technologies (ICTs) is helping to develop other ways to implement these kinds of exercises, as occurs in the clinical psychology field with the emergence of new treatment methods (virtual reality, augmented reality, Internet interventions; Andersson \& Cuijpers, 2009; Opris et al., 2012). Likewise, the use of ICTs has also been suggested to enhance the benefits produced by positive psychology (Botella et al., 2012; Riva, Baños, Botella, Wiederhold \& Gaggioli, 2012). In this regard, the integration of ICTs and Positive Technology has resulted in the emergence of a new field called "Positive Technology" (PT). This approach has been defined as "the scientific and applied approach that uses technology to improve the quality of our personal experience, with the goal of increasing wellness and generating strengths and resilience in individuals, organizations, and society" (Botella et al., 2012; Riva et al., 2012). Thus, PT can be used to influence three specific features of our experience: emotional quality, linked to the generation of positive and pleasant experiences; engagement/actualization, using technology to achieve engaging and self-actualizing experiences; and connectedness, using technology to improve social integration and connectedness (Baños et al., 2014). Moreover, the use of PTs can help to standardize procedures because it allows much more control over the process (Baños et al., 2013). In the present study, we have adapted the BPS exercise for implementation through Positive Technology. In this case, we use this technology to enhance the quality of the experience by providing a more engaging way to perform the exercise.

In sum, this study is designed to investigate whether the BPS exercise applied through positive technologies increases optimistic future thinking beyond two weeks of intervention (Meevissen et al., 2011), and explore the effects on other potentially impacted measures, such as affect and depressive symptoms, after one month of training (Layous, Nelson \& Lyubomirsky, 2013; Sergeant \& Mongrain, 2014). Thus, the main 
goal is to test if the adaptation of the BPS exercise is able to replicate the effects found in other studies in the short- (pre-post session; Peters et al., 2013) and mid-term (15 days; Meevissen et al., 2011), and explore whether these effects are maintained after a training period of one month. In addition, a second goal is to explore whether these effects are maintained at follow-ups measured one and three months later. Finally, the present study explores the acceptance and perceived usefulness of the exercise and the technology used to implement it. Based on these goals, the main hypothesis is that participants of the BPS condition will increase their levels of positive affect, optimism, and future expectations, and reduce depressive symptoms until post-training, compared to a control condition. Given that the second goal is exploratory, no hypothesis has been established with regard to this matter. The third hypothesis is that participants will report high levels of satisfaction with and perceived usefulness about the exercises and about the use of Positive Technologies.

\section{METHOD}

\subsection{Participants}

The total sample was composed of 78 participants, 27 men (34.6\%) and 51 women (65.4\%), mostly students and administrative personnel from the Universitat Jaume I and the Universitat de Valencia. Mean age was 23.8 years $(\mathrm{SD}=3.85)$. Information about the flow of participants through the study is presented in the results section.

\subsubsection{Inclusion and exclusion criteria}

The inclusion criteria used to select the participants were: 1) Aged between 18 and 70 years old, 2) Not suffering from a severe physical illness, 3) Not suffering from a psychological disorder or receiving psychological treatment.

\subsection{Measures}

\section{Primary Outcome}

Positive and Negative Expectations. We used the Spanish adaptation of the Subjective Probability Task (SPT; MacLeod, 1996, Molinari et al., in press). This instrument measures positive and negative expectations about events that will occur in the future. It consists of 30 items, 20 of them related to negative expectations about events that can take place in the future (i.e. "You will have health problems") and 10 referring to positive expectations (i.e. "People will admire you"). The instrument asks individuals to judge the likelihood of an event happening in the future on a 7-point scale (from 1 "Not at all likely to occur to 7 "extremely likely to occur"). Some studies have found appropriate internal consistency levels for positive and negative expectations $(\alpha=0.80$ 0.82 and 0.91, respectively; Meevissen et al., 2011; Peters et al., 2010).

\section{Secondary Outcomes}

Dispositional Optimism. We used the Spanish adaptation of the Life Orientation Test (LOT-R; Otero-López, et al., 1998; Scheier, Carver \& Bridges, 1994). This scale measures the extent to which a person generally expects favorable outcomes. It includes 10 items: 3 items refer to positive expectations (i.e. "I'm always optimistic about my 
future"), 3 items refer to negative expectations (i.e. "I rarely count on good things happening to me"), and 4 items are fillers. Answers are rated on a 5-point scale (from 0 "strongly disagree" to 4 "strongly agree"). Higher scores reflect a higher level of dispositional optimism. Other studies have found an internal consistency for the eight items of $\alpha=0.76$ (Meevissen et al. 2011).

Positive and Negative Affect. To measure affect, we used the Spanish adaptation of the Positive and Negative Affect Scale (PANAS, Sandín et al., 1999; Watson, Clark \& Tellegen, 1988). This instrument is composed of 20 items: 10 items measuring positive affective states (i.e. "Interested") and 10 items measuring negative affect states (i.e. "Irritable"). Participants rate on a five-point scale (from "Not at all" to "Extremely") the degree to which they usually feel a specific affective state. PANAS is one of the most widely-used instruments to measure affect because it shows excellent psychometric properties (Cronbach Alpha's from 0.87-0.91).

Depressive symptoms. The Beck Depression Inventory was used to measure mood levels (BDI-II; Beck, Steer \& Brown, 1996). This is one of the most widely used instruments to assess the severity of depressive symptoms in general and clinical populations. In the present study, the Spanish validation of this instrument was used (Sanz, García-Vera, Espinosa, Fortún \& Vázquez, 2005). It is composed of 21 items designed to assess depression in its different expressions: cognitive, affective, somatic, and behavioral (i.e. sadness, sleep problems, apathy, sex behavior). The time frame referred to in the questions is the past two weeks, and the answers range from 0 (absence of the symptom) to 3 (maximum level of the symptom). This scale has good reliability and internal consistency, with Cronbach's alphas of 0.84-0.89.

Participants' opinions. This scale includes five questions about qualitative data, rated on a Likert scale (from 0 to 10). First, "To what extent has your participation in this imagination exercise been satisfactory?" Second, "To what extent has your participation in this imagination exercise been useful? Third, "To what extent has the use of this technology been satisfactory?" Fourth, "To what extent has the use of this technology been useful?" Finally, "How many days per week did you perform the exercise?"

\subsection{Design}

This is an experimental, repeated-measures study with two independent groups. All participants $(\mathrm{N}=78)$ were randomly assigned to two conditions: 38 to the experimental condition (adaptation of the BPS exercise) and the other 40 to the control condition (Daily Activities). The random assignment of the participants to the different experimental conditions was carried out by an independent researcher who had no knowledge about the study or the intervention received in the different groups. The randomization was performed through a randomization list created by the Random Allocation Software, version 1.0. The participants did not know the characteristics of the different experimental groups. 
The study was registered in the United States National Institute of Health Registration System (http://www.clinicaltrials.gov) with Clinical Trials Registration Number: NCT02321605, https://clinicaltrials.gov/show/NCT02321605. Moreover, the study was approved by the Ethics Committee of Jaume I University.

Six assessment moments were used (see Figure 1): Before the exercise (pre), after the first session (post-session), mid-term training (15 days-training) and post-training. Moreover, we included two follow-ups: one month after finishing the training period ( $1^{\text {st }}$ follow-up) and three months after finishing the training ( $2^{\text {nd }}$ follow-up)

\section{INSERT FIGURE 1}

\subsection{Positive Technology Applications}

Book of Life. This virtual application looks like a personal diary and is composed of different chapters in which users are asked to write about many different topics and support the essay with multimedia content. For this study, a new chapter was created with the BPS instructions, allowing the participants to add pictures, songs, and videos to the BPS essay. Book of Life is a module of the EARTH system, a self-guided platform with different activity modules, each of them designed to induce specific emotions. As a whole, it has shown efficacy in increasing positive mood (Baños et al., 2014; Botella et al., 2016).

TEO (Emotional-Online Therapy). This web platform is designed for use as a tool or a complement in the framework of a therapeutic program (for example: homework assignment; Quero, Molés, Pérez, Botella \& Baños, 2012). It can be used to develop and organize therapeutic contents based on multimedia materials, as well as to create and personalize treatment sessions and protocols. Furthermore, after reading the exercise, participants can access two virtual environments (a forest and a beach), where they can stay as long as they like.

SMS messages: A protocol for sending messages was developed to encourage and remind participants to practice the exercise. The messages were sent through the website www.trendoo.es. in a randomized way, for example: "Happiness is not an ideal based on reason, but rather on imagination. Don't forget to continue to practice the imagination exercise! Thank you very much." or "Hello! You're doing great! We encourage you to continue to practice the imagination exercise. Thank you very much."

PowerPoint: A PowerPoint file was created to write about the activities, feelings and thoughts experienced in the past 24 hours. It included a first slide with the instructions for the exercise, and from that point on, the participant could add slides as he/she tracked the following days.

\subsection{Interventions}

e-BPS: In this condition, participants were asked to write about and imagine a future in which they have reached all their goals and developed all their potential in four different 
domains: personal, professional, social, and health domains. Unlike other studies do not include a health domain (Meevissen et al. 2011), we considered it important for participants to think about what they would have to do to improve or sustain their current level of health, a significant life area.

Participants performed the exercise in the "Book of Life" located in the laboratory. This application was designed so that participants could write and imagine their BPS and incorporate multimedia content (images, music and videos) into the essay, in order to enrich the experience and enhance the content of what they had written. After the first session, all the content included by the participants in the "Book of Life" was exported to the web platform (TEO), so that they could continue to practice the exercise at home in the same format.

Daily activities $(D A)$ : In this condition, participants were asked to think and write about everything they had done in the past 24 hours. These instructions were adapted from the Sheldon and Lyubomirsky (2006). As they performed the exercise, participants were told that it would help them to identify problematic areas in their lives and work on improving them. Participants in this condition were provided with a PowerPoint document on which to write the content of the exercise. They kept this document so that they could continue to write at home.

In both conditions, they were told to write the exercise in the format of a personal story to facilitate visualization. Furthermore, they were given a printed copy of the text they had written and, in the case of the participants in the BPS condition, this copy included the pictures they had added. In both conditions, we asked the participants to continue to practice the same exercise once a day at home for at least five minutes during the rest of the month. As a reminder, SMS messages were delivered weekly for all the participants.

\subsection{Procedure}

Sample recruitment was carried out by placing advertisements at different locations at Jaume I University of Castellon (Spain). The information provided to announce the study was extracted from the experiment performed by Meevissen and colleagues (2011), who designed a slogan to attract people's attention. The advertisement stated that the study consisted of testing "The Power of Visualization", and that it could have a positive influence on mood. Individuals who showed interest in participating in the study contacted us by email or telephone. They were informed about the characteristics of the study, and if they agreed to participate, an appointment was made for the first session. Before the first meeting they were randomly assigned to one of the conditions. When the participants arrived at the laboratory, they signed the informed consent stating that they were participating in the study voluntarily. Later, we briefly explored whether they met the inclusion criteria for the study, and they completed the pre-test questionnaires. After that, the participants received the instructions for the corresponding exercise in audio format and on paper. Next, all the participants were left alone in the room to avoid distractors and stimulate concentration on the exercise. All participants in both conditions prepared the exercise during 20 minutes. In the case of 
BPS condition, if multimedia content was not still selected, participants were encouraged to do it, allowing them to spend a maximum of 5 minutes. When the time was up, all the participants were asked to perform the 5-minute imagery exercise. Specifically in the $e$-BPS condition, individuals performed the imagery exercise through another display of the Book of Life, where they visualized the BPS essay along with the multimedia content selected previously. Regarding the DA condition, participants were asked to read and visualize the content of their essays through the full screen mode of the PowerPoint presentation, in order to reproduce a similar methodology and use the same technology in both conditions.

To finalize the session, all the participants had to fill out the PANAS and SPT again to assess the immediate effects of writing and visualizing the exercise. At the end of this first session, they were asked to continue to practice the exercise 5 minutes a day during a period of one month. During this training period, two brief text messages per week were sent to the participants' mobile phones to encourage them and remind them to perform the exercise once a day. Fifteen days later (mid-term training), participants received and completed online surveys containing a brief follow-up of the LOT-R, SPT and PANAS, in order to compare the results at this time with similar studies (Meevissen et al. 2011).

At the end of the one-month study period (post-training), participants were given an appointment to complete the post-training assessment, including the participant opinion scale. Finally, participants were contacted online one and three months later to complete the follow-up assessments ( $1^{\text {st }}$ and $2^{\text {nd }}$ follow-up). It is important to note that, during the follow-up period, participants were encouraged to continue to practice the exercise, but they were not instructed to perform it daily. Instead, they were told that they could decide how many days they would practice it, although we encouraged them to do so at least two or three days a week to maintain the habit. These instructions were given, regardless of the assigned condition. Furthermore, one text message per week was sent during the follow-up with the same content as the SMS sent during the one-month training.

\subsection{Data analyses}

Analyses were separated by measurement moments in order to check the efficacy of the intervention at different time points. Therefore, we divided the analyses into pre- and post-session assessments to analyze the single-session effects, and other analyses were performed with the other time assessments to explore the efficacy over time.

One-way analysis of variance (ANOVAs) was performed to find out whether there were significant differences between the groups in demographic data and pre-treatment measures. Mixed ANOVA with repeated measures were used to compare the effects of the intervention on the measures between the two conditions at the different time points.

In order to improve the quality of the study and following the CONSORT guidelines, intent-to-treat (ITT) analyses were carried out. These analyses make it possible to use 
all the available data from all the randomized subjects who received the allocated intervention ( $n=78$; Gupta, 2011). For the treatment of missing data, the procedure suggested by Hair and colleagues (2014) was followed. First, the type of missing data was explored, concluding that they were missing data at item-level and, thus, eligible for imputation. Second, the quantity of missing values was analyzed, determining that any of the measures had more than $21 \%$ missing values. Third, a diagnosis of the random pattern of missing data was carried out through the Little MCAR test $\left(\chi^{2}(1110)\right.$ $=634.96, p>0.05)$; Little \& Rubin, 1990). This test concluded that the missing data were due to chance, and not to any other factor registered in the database. Finally, maximum likelihood estimation (ML) was performed for the missing values, and sensitivity analysis comparing results of the completers with the estimated values. These analyses showed that there was no chance of falling into biased estimations by using the maximum likelihood estimation.

We analyzed single-session effects (pre-post-session), through a $2 \times 2$ ANOVA, to compare the effects of the intervention on affect and future expectations in the BPS and DA conditions. Next, effects over time were explored by carrying out a 5x2 ANOVA for each measure (Pre - 15-days-training - Post-Training - $1{ }^{\text {st }}$ Follow-up - $2{ }^{\text {nd }}$ Followup). Finally, effect sizes (Cohen's d) and confidence intervals were calculated for within-group changes, based on the formula provided by Botella and Sanchez-Meca (2015). Reporting the effect size strengthens the reliability of the observed changes because it is the best indicator to assess the magnitude of the findings in research studies (Durlak, 2009).

Moreover, we analyzed the participants' opinions collected through the scale. Specifically, the levels of satisfaction and usefulness of the exercises and the technology were explored, as well as the frequency of the exercise. We calculated the average scores provided by the participants, and we compared the differences between conditions through independent-samples t-tests.

\section{RESULTS}

\subsection{Participant Flow}

Regarding the flow of participants throughout the investigation process, Figure 2 shows that 89 people were interested in the study. Eight of them did not participate in the first session because they were ultimately not interested $(n=6)$, or they did not answer the phone call $(n=2)$. A total of 81 participants were assigned to the two experimental conditions: $e$-BPS, $\mathrm{n}=40 ; \mathrm{DA}, \mathrm{n}=41$. Of them, 3 people did not attend the first session $(2$ from the $e$-BPS condition and 1 from the control condition), and so the total sample that received the intervention consisted of 78 participants.

\section{INSERT FIGURE 2}

\subsection{Pre-Treatment Data}


Differences in pre-test scores between conditions were explored through one-way ANOVA. These analyses revealed no significant differences between conditions before treatment on any of these variables: SPT-POS $(\mathrm{F}[1,76]=1.25 ; \mathrm{p}=0.267)$, SPT-NEG $(\mathrm{F}[1,76]=0.681 ; \mathrm{p}=0.412), \mathrm{PA}(\mathrm{F}[1,76]=0.431 ; \mathrm{p}=0.514), \mathrm{NA}(\mathrm{F}[1,76]=0.876 ; \mathrm{p}=0.352)$, LOT-R $(\mathrm{F}[1,76]=1.225 ; \mathrm{p}=0.272)$ and BDI $(\mathrm{F}[1,76]=0.031 ; \mathrm{p}=0.860)$. These findings indicate that the random assignment was successful. In addition, applying the same analysis, no significant differences were found based on participants' sex $\left(\chi^{2}(1)=0.162\right.$; $p=0.687)$ or age $(\mathrm{F}[1,76]=0.438 ; \mathrm{p}=0.510)$.

\subsection{Intervention effects}

\subsubsection{Pre-post-session effects (Single-session effects)}

To analyze single-session effects, we conducted a repeated-measures mixed ANOVA on the SPT and PANAS questionnaires. Results showed significant time effects for all the measures included: SPT-POS $(\mathrm{F}(1,76)=26.91, \mathrm{p}=0.001)$, SPT-NEG $(\mathrm{F}(1,76)=$ 41.98, $\mathrm{p}=0.001)$, PA $(\mathrm{F}(1,76)=31.58, \mathrm{p}=0.001)$ and $\mathrm{NA}(\mathrm{F}(1,76)=4.92, \mathrm{p}=0.03)$. Interaction effects were found for the two variables of the SPT, namely SPT-POS $(\mathrm{F}(1,76)=9.85, \mathrm{p}=0.002)$ and SPT-NEG $(\mathrm{F}(1,76)=10.75, \mathrm{p}=0.002)$, showing that the BPS exercise was more effective in increasing positive expectations and decreasing negative ones, compared to the control exercise. However, no significant interaction effects were found for PA $(\mathrm{F}(1,76)=3.12, \mathrm{p}=0.081)$ or $\mathrm{NA}(\mathrm{F}(1,76)=0.62, \mathrm{p}=0.432)$, as there was a change in the scores after the first session, but with no significant differences between conditions.

Figure 3 and 4 shows the graph of the change in scores for BPS and control conditions, as well as the effect size (measured by Cohen's $d$; Cohen, 1988) for both measures. As the figure shows, in the case of the $e$-BPS condition, a significant moderate effect size (at 95\% confidence intervals) was found for SPT-POS, SPT-NEG and PA, and a nonsignificant small effect size for NA. For the control condition, effect sizes did not reach significance for any of the measures, although a small effect size was found for PA.

\section{INSERT FIGURE 3-4}

\subsubsection{Effects on the different time point assessments}

Table 1 shows the means, standard deviations, and within-group effect sizes for midterm, post-training, and follow-up effects in both experimental conditions.

We carried out a 5x2 ANOVA (Pre-15-days training - Post-Training- ${ }^{\text {st }}$ Followup $-2^{\text {nd }}$ Follow-up) of the different measures. We found a significant time effect on the SPT-POS $(\mathrm{F}(1,76)=3.45, \mathrm{p}=0.012)$, SPT-NEG $(\mathrm{F}(1,76)=7.02, \mathrm{p}=0.001), \mathrm{PA}(\mathrm{F}(1,76)=$ 3.46, $\mathrm{p}=0.012)$ NA $(\mathrm{F}(1,76)=5.63, \mathrm{p}=0.001)$ and $\mathrm{BDI}(\mathrm{F}(1,76)=11.29, \mathrm{p}=0.001)$, indicating that a significant change in scores over time had been produced in both conditions. The time effect was non-significant in the case of LOT-R $(\mathrm{F}(1,76)=1.38$, $\mathrm{p}=0.249$ ), indicating that the change in both conditions was non-significant over time. ANOVA analysis did not show any significant interaction effects for any of the 
measures. Regarding the effect size (Table 1), in the case of the $e$-BPS condition, it is possible to observe a continued increase in the effect size during the training (15 days to post-training) on the SPT, PANAS and BDI measures, and this was more pronounced in the case of SPT-NEG and BDI, where a moderate effect size was found. The effects on these measures were maintained until the first follow-up and disappeared in the second follow-up, with the exception of BDI, whose effects were maintained in the second follow-up. In the case of the control condition, we also found a small effect size on the SPT-POS, PANAS and BDI at post-training, and these effects were also maintained in the first follow-up, with the exception of the SPT-POS, whose results disappeared in both follow-ups. In the case of BDI, the scores reached a moderate effect size at the first follow-up, but the effect size became small in the second follow-up.

\section{INSERT TABLE 1}

\subsection{Participants' opinion}

Regarding the participants' opinions, we carried out independent-samples t-tests between conditions on the questions about satisfaction and usefulness. For the exercise, we did not find any significant differences between conditions. All the participants showed high levels of satisfaction $(\mathrm{M}=7.59, \mathrm{SD}=1.5$ for the $e$-BPS condition, and $\mathrm{M}=7.21, \mathrm{SD}=1.91$ for the control condition), and they referred to finding the exercise useful $(\mathrm{M}=7.21, \mathrm{SD}=1.71$ for the $e$-BPS condition, and $\mathrm{M}=6.94, \mathrm{SD}=1.86$ for the control condition).

In the case of the use of Positive Technologies, the Book of Life was rated significantly higher than the PowerPoint on usefulness $(\mathrm{t}=2.62, \mathrm{p}=0.01)$ and satisfaction $(\mathrm{t}=2.66$, $\mathrm{p}=0.01$ ). Regarding the descriptive data, the Book of Life was considered very useful $(M=8.03$, SD: 1.61$)$, and participants felt highly satisfied with its use $(M=8.00$, $\mathrm{SD}=1.44)$. The TEO system also received appropriate scores on usefulness $(\mathrm{M}=6.92$, $\mathrm{SD}=2.21)$ and satisfaction $(\mathrm{M}=7.12, \mathrm{SD}=2.03)$. The PowerPoint was also considered useful $(M=6.45, S D=3.00)$, and participants felt satisfied with it $(M=6.79, S D=2.15)$.

Regarding the frequency of the exercise (figure 5), an ANOVA showed a significant time effect $(F[1,56]=47.5, \mathrm{p}<.01)$, indicating a decrease in the scores over time for both conditions (Figure 4$)$. No differences between conditions were found $(F[1,56]=1.1$, $\mathrm{p}=0.34)$.

\section{INSERT FIGURE 5}

\section{DISCUSSION}

In this study, we analyzed the efficacy of an adaptation of the BPS intervention implemented through positive technology ( $e$-BPS) in improving future expectations, optimism, positive affect, and depressive symptoms, compared to a control condition. These effects were explored at short, mid- and long-term and acceptance and utility levels of the exercises and the technologies were also collected. 
Regarding our first hypothesis, the results indicate that the $e$-BPS intervention was able to replicate the significant improvement in future expectations after a single session, compared to the control condition (Peters et al. 2010; Meevissen et al. 2011). However, in the case of affect, no significant differences between conditions were found, although the effect size for positive affect showed a significant moderate effect size in the $e$-BPS condition, whereas a non-significant small effect size was found for the control condition.

Considering the effects at fifteen days and at post-training, there was an overall improvement trend in the different measures, but there were no differences between conditions in any of the measures. Regarding the effect sizes at post-training, they were higher for the $e$-BPS condition, ranging from significant small to moderate effect sizes for future expectations and for positive affect. The effect sizes found in this study are similar to the results reported in prior studies (from small to moderate), except that they found significant differences between conditions (Meevissen et al., 2011; Sheldon \& Lyubomirsky, 2006). However, no change was found in dispositional optimism during the first month in either condition, indicating that the exercise was not powerful enough to produce any effects, unlike in the findings by Meevissen and colleagues (2011). Otherwise, the moderate effect size for the depressive symptoms confirms that this exercise could have a positive impact on the negative and pessimistic view of the personal future in depressive patients, as prior literature suggests (Pietrowsky \& Mikutta, 2012; Sergeant \& Mongrain, 2014).

In the case of the control condition (daily activities), some benefits were observed in the participants in these time frames. Specifically, negative future expectations and negative affect reached a significant small effect size at post-training that was maintained in the case of negative affect until the first follow-up. These results could explain the lack of significant differences between conditions in the ANOVA, as they both obtained changes. Thus, positive effects of thinking and writing about daily activities could be explained by the fact that reflecting about the events that happened during the day could create a higher level of awareness of the good and bad moments. The inclusion of the PowerPoint to perform the exercise might also have contributed to these effects, as it could provide a good framework for writing. This result is consistent with the study by Pennebaker (1993), who showed that, independently of the emotional content of the writing, enhancing the use of words that express awareness or are related to cognitive activity was linked to improvements in health. Furthermore, other studies also showed that the daily activities exercise was able to improve dysfunctional attitude levels (Renner, Schwarz, Peters \& Huibers, 2014) and diminish negative affect (Sheldon \& Lyubomirsky, 2006). For this reason, it would be interesting to choose another more innocuous control activity in order to test the effects in a fairer way.

With regard to the second hypothesis, we explored whether these effects could be maintained at the one- and three-month follow-ups. Results for the $e$-BPS condition showed maintenance of the changes in future expectations, affect, and depressive symptoms until the first follow-up, although only negative expectations and positive 
affect remained significant. However, nearly all of these effects disappeared at the second follow-up; only the scores on depressive symptoms continued to decrease over time in both conditions, especially in the $e$-BPS condition. Thus, although the study sample was composed of university students, and depression levels were low, a tendency toward reductions in these scores over time was observed. Regarding the disappearance of the effects at the second follow-up, these results were similar to the effects on subjective well-being shown by Lyubomirsky et al. (2011), where the performance of the exercise 8 months later did not show significant effects on wellbeing, compared to a control condition.

Regarding the third hypothesis, the performance of the BPS and the Daily Activities was rated as satisfactory and useful for all the participants. These results suggest that the motivation to do the exercises was high, and that they enjoyed and took advantage of them. Participants also rated the Positive Technology Applications as useful and satisfactory. However, satisfaction and usefulness levels were significantly higher for the Book of Life than for the PowerPoint. These results support arguments about the complementary role that ICTs can play in the positive psychology approach (Botella et al., 2012; Riva et al., 2012). In this regard, technologies can add some advantages, as they help to standardize the procedure or, in contrast, carry out controlled modifications to make it a more attractive and engaging activity for users. Along these lines, the importance of these findings lies in the need for interventions that can fit the profiles and features of different people (Lyubomirsky \& Layous, 2013). Therefore, this intervention could be more effective in people who prefer to use ICTs.

Collected data in regard to the reported frequency of performing the exercises showed that, in both conditions, participants continued to practice the exercise weekly, even in the follow-up periods, when they were only invited to continue to do the exercise two or three days a week. Even with the reduction during the follow-up, the observed frequency is indicative of participants' willingness to do the exercise. This, it is possible that participants did not find it necessary to perform the exercise more than two or three times a week to obtain benefits. Based on a habit formation model, lapses of one week would be indicative of greater difficulties in maintaining a specific behavior (Armitage, 2005). In this case, the fact that the exercise was performed more than two days a week during the follow-up period could be a good prognosis for future performance and the maintenance of the habit. It would be interesting to find an optimal balance between the performance rate and the benefits, in order to discover the minimum frequency necessary to maintain the effects.

The present study contributes to the positive psychology literature because it not only explores long-term effects of a PPI, but it also conducts intent-to-treat analyses for handling missing values. Both aspects are crucial indicators of the methodological quality of the studies, and they have a direct impact on the validity and generalization of the results (Rothwell, 2006; Schulz, Altman \& Moher, 2010). However, only about one fourth of the studies with PPIs explore long-term effects, and they rarely conduct intentto-treat analyses (Bolier et al. 2013). Attending to the observed weakening of the 
outcomes over time, it could be explained by one of the mediator variables of PPIs proposed by Lyubomirsky and Layous (2013), the variety. These authors propose a set of factors that could affect the efficacy of the exercise. In the present study, the BPS manipulation consisted of repeating the exercise of visualizing the best possible future for four months, based on the essay edited in the first session. This situation could produce the phenomenon called hedonic adaptation (Diener, Lucas \& Scollon, 2006), where the exercise no longer produces the same benefits as it did in the beginning. Taking the prior literature into account, factors like variety (Lyubomirsky \& Layous, 2013) could help to avoid the hedonic adaptation that these exercises usually produce (Diener et al. 2006). Therefore, we should think about the possibility of improving positive psychological interventions by making them more varied and tailored to each participant. In this sense, our team has designed a program for the improvement of positive processes and traits related to the future by mixing optimistic thinking (BPS exercise) and the components of hope therapy, in order to improve the variety of the intervention and sustain the effects in the long term (Enrique, Molinari, Llorca \& Botella, 2016).

This study has some limitations. Participants may have been biased by the information received before the study. The advertising used to catch their attention stated that performing the exercise could have a positive influence on their mood. However, the information was extracted from other studies where it had no effect on the results (Meevissen et al. 2011; Sheldon \& Lubomirsky, 2006). Future studies should try to control this variable, as in the study by Layous and colleagues (2012). They compared the efficacy of the BPS exercise in participants who read false testimonials about the benefits of the exercise and participants who read neutral information. Results showed that greater gains in well-being were obtained by participants who read the false testimonials, which suggests the importance of expectations in the actual efficacy of the intervention. Furthermore, the control condition focuses on the past 24 hours, unlike the BPS exercise, which is oriented towards the future. Therefore, further studies should include a control condition with the same temporal orientation in order to compare the results. Despite the innovative design of the intervention, it is important to note that the efficacy of the technologies was not compared to a condition without technologies, which means we cannot know the differential role of the technology in the implementation of the BPS exercise. Moreover, the decrease in depressive symptoms observed during the training and follow-up supports the link between depressive symptoms and future expectations (Beck \& Haigh, 2014; Rief et al. 2015). In this regard, the study sample was composed of young students with low scores on depressive symptoms and negative affect, which might make it more difficult to observe changes in these measures because of floor effects. As Sergeant and Mongrain (2015) showed, individuals suffering from emotional distress benefit more from PPIs than healthy adults. For this reason, it would be interesting to carry out studies with clinical populations with higher depressive symptoms in order to find out whether the BPS exercise is also able to reduce depressive symptoms. Overall, we can say that the BPS 
exercise might be included as a way to prevent emotional problems, beyond improving positive affect and well-being.

Future studies could also explore the effects of the BPS exercise on other constructs related to eudaimonic well-being and goal pursuit, such as self-efficacy or purpose in life (Ryan \& Deci, 2001). Furthermore, it would be important to develop new more sensitive instruments to change, such as a measure of state optimism, similar to the state hope scale (Snyder et al., 1996). These instruments would make it possible to analyze the real impact of these interventions on optimism because dispositional optimism is too stable to detect short-term changes (Liau, Neihart, Teo \& Lo, 2016; Pietrowsky \& Mukutta, 2012). Moreover, the inclusion of other types of measures, such as Ecological Momentary Assessment strategies, could help to perform a much more accurate assessment (Trull \& Ebner-Priemer, 2009).

In conclusion, in the field of positive psychology, further research is needed about basic aspects such as the development of procedures, and interventions designed to enhance specific positive features and the implementation of high-quality methodological designs. In this sense, this study provides important information about the efficacy of BPS exercise in a controlled study. Nevertheless, the progress in the field in the past decade shows new developments that allow us to understand the BPS experience and, thus, the conditions and processes that contribute to the emergence of positive feelings.

\section{REFERENCES}

Andersson, G., \& Cuijpers, P. (2009). Internet-based and other computerized psychological treatments for adult depression: a meta-analysis. Cognitive behaviour therapy, 38(4), 196-205. doi: 10.1080/16506070903318960.

Armitage, C. J. (2005). Can the theory of planned behavior predict the maintenance of physical activity? Health Psychology, 24(3), 235. doi: 10.1037/0278-6133.24.3.235.

Baños, R. M., Espinoza, M., García-Palacios, A., Cervera, J. M., Esquerdo, G., Barrajón, E., \& Botella, C. (2013). A positive psychological intervention using virtual reality for patients with advanced cancer in a hospital setting: a pilot study to assess feasibility. Supportive Care in Cancer, 21(1), 263-270. doi: 10.1007/s00520-012-1520$\mathrm{X}$.

Baños, R. M., Etchemendy, E., Farfallini, L., García-Palacios, A., Quero, S., \& Botella, C. (2014). EARTH of Well-Being System: A pilot study of an Information and Communication Technology-based positive psychology intervention. The Journal of Positive Psychology, 9(6), 482-488. doi: 10.1080/17439760.2014.927906.

Beck, A. T., \& Haigh, E. A. (2014). Advances in cognitive theory and therapy: The generic cognitive model*. Annual Review of Clinical Psychology, 10, 1-24. doi: 10.1146/annurev-clinpsy-032813-153734.

Beck, A. T., Steer, R. A., \& Brown, G. K. (1996). BDI-II manual (2nd edition). San Antonio, TX: Psychological Corporation.

Boehm, J. K., Lyubomirsky, S., \& Sheldon, K. M. (2011). A longitudinal experimental study comparing the effectiveness of happiness-enhancing strategies in Anglo 
Americans and Asian Americans. Cognition \& Emotion, 25(7), 1263-1272. doi: 10.1080/02699931.2010.541227.

Bolier, L., Haverman, M., Westerhof, G. J., Riper, H., Smit, F., \& Bohlmeijer, E. (2013). Positive psychology interventions: a meta-analysis of randomized controlled studies. BMC public health, 13(1), 119. doi: 10.1186/1471-2458-13-119.

Botella, C., Baños, R. M., Etchemendy, E., García-Palacios, A., \& Alcañiz, M. (2016). Psychological countermeasures in manned space missions:"EARTH" system for the Mars-500 project. Computers in Human Behavior, 55, 898-908.

Botella, C., Riva, G., Gaggioli, A., Wiederhold, B. K., Alcaniz, M., \& Baños, R. M. (2012). The present and future of positive technologies. Cyberpsychology, Behavior, and Social Networking, 15(2), 78-84. doi: 10.1089/cyber.2011.0140.

Botella, J. \& Sánchez-Meca (2015). Meta-análisis en ciencias sociales y de la salud. Madrid: Síntesis

Cohen, J. (1988). Statistical Power Analysis for the Behavioral Sciences, 2nd ed. Hillsdale, New Jersey: Erlbaum.

Diener, E., Lucas, R. E., \& Scollon, C. N. (2006). Beyond the hedonic treadmill: revising the adaptation theory of well-being. American Psychologist, 61(4), 305. doi: 10.1037/0003-066x.61.4.305.

Durlak, J. A. (2009). How to select, calculate, and interpret effect sizes. Journal of Pediatric Psychology, 34, 917-928. doi: 10.1093/jpepsy/jsp004.

Enrique, A., Molinari, G., Llorca, G. \& Botella, C. (2016). "Mi Mejor Yo": Diseño de una intervención positiva aplicada en formato grupal y apoyada en las TICs. Agora de Salut, 3, 121-129. doi: 10.6035/agorasalut.2016.3.13.

Gupta, S. K. (2011). Intention-to-treat concept: a review. Perspectives in clinical research, 2(3), 109. doi: 10.4103/2229-3485.83221.

Hair, J. F., Black, W. C., Babin, B. J. \& Anderson, R. E. (2014). Multivariate data analysis ( $7^{\text {th }}$ Ed.). River, NJ: Pearson-Prentice Hall. International Edition.

King, L. A. (2001). The health benefits of writing about life goals. Personality and Social Psychology Bulletin, 27(7), 798-807. doi: 10.1177/0146167201277003.

King, L. A., \& Raspin, C. (2004). Lost and Found Possible Selves, Subjective Well-Being, and Ego Development in Divorced Women. Journal of personality, 72(3), 603-632. doi: 10.1111/j.0022-3506.2004.00274.x.

Layous, K., Nelson, S. K., \& Lyubomirsky, S. (2012). What is the optimal way to deliver a positive activity intervention? The case of writing about one's best possible selves. Journal of Happiness Studies, 14(2), 635-654. doi: 10.1007/s10902-012-9346-2.

Liau, A. K., Neihart, M. F., Teo, C. T., \& Lo, C. H. (2016). Effects of the best possible self activity on subjective well-being and depressive symptoms. The Asia-Pacific Education Researcher, 1-9. doi: 10.1007/s40299-015-0272-z.

Little, R. L. y Rubin, D. B. (1990). Statistical analysis with missing data. New York: Wiley. 
Lyubomirsky, S., \& Layous, K. (2013). How do simple positive activities increase wellbeing? Current Directions in Psychological Science, 22(1), 57-62. doi: 10.1177/0963721412469809.

Lyubomirsky, S., Dickerhoof, R., Boehm, J. K., \& Sheldon, K. M. (2011). Becoming happier takes both a will and a proper way: an experimental longitudinal intervention to boost well-being. Emotion, 11(2), 391. doi: 10.1037/a0022575.

MacLeod, A.K. (1996). Affect, emotional disorder, and future-directed thinking. Cognition \& Emotion, 10, 69-86. doi: 10.1080/026999396380394.

Meevissen, Y. M., Peters, M. L., \& Alberts, H. J. (2011). Become more optimistic by imagining a best possible self: Effects of a two week intervention. Journal of behavior therapy and experimental psychiatry, 42(3), 371-378. doi: 10.1016/j.jbtep.2011.02.012.

Molinari, G., Dragomir-Davis, A.M., Enrique, A., García-Palacios, A., Baños, R.M. \& Botella, C. (in press). The contribution of future-directed thinking to affect dimensions: differences in general and clinical populations.

Opris, D., Pintea, S., García-Palacios, A., Botella, C., Szamosközi, S., y David, D. (2012). Virtual reality exposure therapy in anxiety disorders: A quantitative metaanalysis. Depression and Anxiety, 29(2), 85-93. doi: 10.1002/da.20910.

Otero, J.M., Luengo, A., Romero, E., Gómez, J.A. \& Castro, C. (1998). Psicología de personalidad. Manual de prácticas. Barcelona: Ariel Practicum

Pennebaker, J. W. (1993). Putting stress into words: Health, linguistic, and therapeutic implications. Behaviour research and therapy, 31(6), 539-548. doi: 10.1016/00057967(93)90105-4.

Peters, M. L., Flink, I. K., Boersma, K., \& Linton, S. J. (2010). Manipulating optimism: Can imagining a best possible self be used to increase positive future expectancies? The Journal of Positive Psychology, 5(3), 204-211. doi: 10.1080/17439761003790963.

Peters, M. L., Meevissen, Y. M., \& Hanssen, M. M. (2013). Specificity of the Best Possible Self intervention for increasing optimism: Comparison with a gratitude intervention. Terapia Psicologica, 31(1), 93-100. doi: 10.4067/s071848082013000100009.

Pietrowsky, R., \& Mikutta, J. (2012). Effects of positive psychology interventions in depressive patients-A randomized control study. Psychology, 3(12), 1067. doi: 10.4236/psych.2012.312158.

Quero, S., Molés, M., \& Pérez-Ara, M. A. Botella \& Baños. RM (2012). An Online Emotional Regulation System to deliver homework assignments for treating Adjustment Disorders. Annual Review of Cybertherapy and Telemedicine: Advanced Technologies in the Behavioral, Social and Neurosciences. 2012, 181:273-7.

Renner, F., Schwarz, P., Peters, M. L., \& Huibers, M. J. (2014). Effects of a bestpossible-self mental imagery exercise on mood and dysfunctional attitudes. Psychiatry research, 215(1), 105-110. doi: 10.1016/j.psychres.2013.10.033.

Rief, W., Glombiewski, J. A., Gollwitzer, M., Schubö, A., Schwarting, R., \& Thorwart, A. (2015). Expectancies as core features of mental disorders. Current opinion in psychiatry, 28(5), 378-385. doi: 10.1097/yco.0000000000000184.

Riva, G., Baños, R. M., Botella, C., Wiederhold, B. K., \& Gaggioli, A. (2012). Positive technology: using interactive technologies to promote positive functioning. 
Cyberpsychology, Behavior, and Social Networking, 15(2), 69-77. doi: 10.1089/cyber.2011.0139.

Rothwell, P. M. (2006). Factors that can affect the external validity of randomised controlled trials. PLOS Clin Trial, 1(1), e9. doi: 10.1371/journal.pctr.0010009.

Ryan, R. M., \& Deci, E. L. (2001). On happiness and human potentials: A review of research on hedonic and eudaimonic well-being. Annual review of psychology, 52(1), 141-166. doi: 10.1146/annurev.psych.52.1.141.

Sandín, B., Chorot, P., Lostao, L., Joiner, T., Santed, M. \& Valiente, R.M. (1999). Escala PANAS de afecto positivo y negativo: Validación factorial y convergencia transcultural. Psicothema, 11, 37-51.

Sanz, J., García-Vera, M. P., Espinosa, R., Fortún, M., \& Vázquez, C. (2005). Adaptación española del Inventario para la Depresión de Beck-II (BDI-II): 3. Propiedades psicométricas en pacientes con trastornos psicológicos. Clínica y salud, 16, 121-142.

Scheier, M., Carver, C. \& Bridges, M. (1994). Distinguishing optimism from neuroticism (and trait anxiety, self-mastery, and self-esteem): A reevaluation of the Life Orientation Test. Journal of Personality and Social Psychology, 67, 1063-1078. doi: 10.1037//0022-3514.67.6.1063.

Schulz, K. F., Altman, D. G., \& Moher, D. (2010). CONSORT 2010 statement: updated guidelines for reporting parallel group randomised trials. BMC medicine, 8(1), 1. doi: 10.1186/1745-6215-11-32.

Sergeant, S., \& Mongrain, M. (2014). An online optimism intervention reduces depression in pessimistic individuals. Journal of consulting and clinical psychology, 82(2), 263. doi: 10.1037/a0035536.

Sheldon, K. M., \& Lyubomirsky, S. (2006). How to increase and sustain positive emotion: The effects of expressing gratitude and visualizing best possible selves. The Journal of Positive Psychology, 1(2), 73-82. doi: 10.1080/17439760500510676.

Sin, N. L., \& Lyubomirsky, S. (2009). Enhancing well-being and alleviating depressive symptoms with positive psychology interventions: A practice-friendly meta-analysis. Journal of clinical psychology, 65(5), 467-487. doy: 10.1002/jclp.20593.

Snyder, C. R., Sympson, S. C., Ybasco, F. C., Borders, T. F., Babyak, M. A., \& Higgins, R. L. (1996). Development and validation of the State Hope Scale. Journal of personality and social psychology, 70(2), 321.

Trull, T. J., \& Ebner-Priemer, U. W. (2009). Using experience sampling methods/ecological momentary assessment (ESM/EMA) in clinical assessment and clinical research: introduction to the special section. Psychological Assessment, 21(4), 457-462. doi: 10.1037/a0017653.

Watson, D., Clark, L. \& Tellegen, A. (1988). Development and validation of brief measures of positive and negative affect: The PANAS scales. Journal of Personality and Social Psychology, 54, 1.063-1.070. doi: 10.1037//0022-3514.54.6.1063. 
Efficacy of $e$-BPS: An adaptation of the Best possible Self exercise implemented through positive technology. A Randomized Control Trial

Enrique, Ángel $^{\mathrm{a}}$ (aenrique@uji.es; Tel: +34 964055125), Bretón-López, Juana ${ }^{\mathrm{a}, \mathrm{b}}$ (breton@uji.es; Tel: +34 964387642), Molinari, Guadalupea (molinari@uji.es; Tel: +34 964387645); Baños, Rosa M. ${ }^{\text {b,c }}$ (banos@uv.es; +34 963864412) and Botella, Cristina ${ }^{\text {a,b }}$ (botella@uji.es; Tel: +34 964387639)

a Department of Basic Psychology, Clinic and Psychobiology, University Jaume I, Castellón, Spain

${ }^{\mathrm{b}}$ CIBER Fisiopatología Obesidad y Nutrición (CIBERobn), Instituto Salud Carlos III, Spain

c Department of Personality, Evaluation and Psychological Treatment, Valencia University, Valencia, Spain

\section{Corresponding author at}

Jaume I University, Labpsitec, Spain, Av. Sos Baynat s/n, 12071 Castellón, Spain.

Tel.: +34 964387644

e-mail address: aenrique@uji.es (Angel Enrique).

Conflict of Interest: The authors declare that they have no conflict of interest. 
Table 1. Means, standard deviations and within-group effect sizes for the outcome measures in the different time-point assessments

\begin{tabular}{|c|c|c|c|c|c|c|c|c|c|c|}
\hline & & & Mean (SD) & & $\begin{array}{c}\text { Within-group } \\
\text { effect size, } d \\
{[95 \% \mathrm{CI}]}\end{array}$ & $\begin{array}{c}\text { Within-group } \\
\text { effect size, } d \\
{[95 \% \mathrm{CI}]}\end{array}$ & Mear & SD) & & \\
\hline & & Pre & $\begin{array}{l}\text { 15-Days } \\
\text { Training }\end{array}$ & $\begin{array}{l}\text { Post- } \\
\text { Training }\end{array}$ & $\begin{array}{l}\text { Pre-15-Days } \\
\text { Training }\end{array}$ & $\begin{array}{l}\text { Pre_Post- } \\
\text { Training }\end{array}$ & $1^{\text {st }}$ Follow-Up & $\begin{array}{l}2^{\text {nd }} \text { Follow- } \\
\text { Up }\end{array}$ & Pre $-1^{\text {st }} \mathrm{F}-\mathrm{Up}$ & Pre $-2^{\text {nd }} F-U p$ \\
\hline \multirow{3}{*}{$\begin{array}{l}\text { SPT- } \\
\text { POS }\end{array}$} & BPS & $5.12(0.88)$ & $5.22(0.92)$ & $5.42(0.77)$ & $0.11[-0.43-0.21]$ & $0.33[0.02-0.64]^{*}$ & $5.39(0.85)$ & $5.28(0.93)$ & $0.30[-0.03-0.64]$ & $0.18[-0.13-0.49]$ \\
\hline & DA & $5.34(0.85)$ & $5.29(0.66)$ & $5.51(0.57)$ & $0.06[-0.25-0.37]$ & $0.20[-0.10-0.49]$ & $5.39(0.78)$ & $5.51(0.69)$ & $0.06[-0.26-0.38]$ & $0.20[-0.11-0.50]$ \\
\hline & Total & $5.23(0.87)$ & $5.26(0.79)$ & $5.47(0.68)$ & & & $5.39(0.81)$ & $5.40(0.82)$ & & \\
\hline \multirow{3}{*}{$\begin{array}{l}\text { SPT- } \\
\text { NEG }\end{array}$} & BPS & $2.88(0.93)$ & $2.54(0.88)$ & $2.41(0.83)$ & $0.36[0.11-0.61]^{*}$ & $0.50[0.22-0.76]^{*}$ & $2.48(0.86)$ & $2.75(0.91)$ & $0.42[0.10-0.74]^{*}$ & $0.14[-0.17-0.45]$ \\
\hline & DA & $2.69(1.08)$ & $2.43(1.02)$ & $2.42(0.97)$ & $0.24[0.01-0.47]^{*}$ & $0.25[0.01-0.48]^{*}$ & $2.54(1.09)$ & $2.67(1.22)$ & $0.14[-0.16-0.43]$ & $0.02[-0.29-0.32]$ \\
\hline & Total & $2.78(1.01)$ & $2.48(0.95)$ & $2.41(0.90)$ & & & $2.52(0.98)$ & $2.71(1.08)$ & & \\
\hline \multirow{3}{*}{ PA } & BPS & $3.06(0.77)$ & $3.32(0.75)$ & $3.37(0.72)$ & $0.33[0.02-0.64]^{*}$ & $0.39[0.08-0.70]^{*}$ & $3.37(0.72)$ & $3.26(0.72)$ & $0.39[0.07-0.72]^{*}$ & $0.25[-0.11-0.62]$ \\
\hline & DA & $3.18(0.79)$ & $3.21(0.62)$ & $3.36(0.66)$ & $0.04[-0.33-0.25]$ & $0.22[-0.07-0.51]$ & $3.39(0.61)$ & $3.37(0.83)$ & $0.26[-0.05-0.57]$ & $0.24[-0.12-0.59]$ \\
\hline & Total & $3.12(0.78)$ & $3.26(0.69)$ & $3.37(0.68)$ & & & $3.38(0.66)$ & $3.27(0.88)$ & & \\
\hline \multirow{3}{*}{ NA } & BPS & $1.59(0.46)$ & $1.56(0.37)$ & $1.49(0.36)$ & $0.09[-0.16-0.33]$ & $0.23[-0.02-0.49]$ & $1.52(0.46)$ & $1.66(0.42)$ & $0.17[-0.15-0.48]$ & $-0.13[-0.50-0.25]$ \\
\hline & DA & $1.72(0.67)$ & $1.66(0.66)$ & $1.53(0.56)$ & $0.09[-0.15-0.33]$ & $0.28[0.02-0.53]^{*}$ & $1.47(0.48)$ & $1.60(0.57)$ & $0.37[0.04-0.69]^{*}$ & $0.18[-0.19-0.54]$ \\
\hline & Total & $1.66(0.58)$ & $1.62(0.56)$ & $1.51(0.47)$ & & & $1.50(0.47)$ & $1.68(0.57)$ & & \\
\hline \multirow{3}{*}{$\begin{array}{l}\text { LOT- } \\
\text { R }\end{array}$} & BPS & $15.63(5.42)$ & $15.81(4.87)$ & $15.77(5.45)$ & $0.03[-0.28-0.21]$ & $0.03[-0.25-0.20]$ & $16.34(3.81)$ & $17.23(3.63)$ & $0.13[-0.21-0.47]$ & $0.29[-0.01-0.59]$ \\
\hline & DA & $16.82(4.04)$ & $16.74(4.50)$ & $17.39(3.65)$ & $0.02[-0.22-0.26]$ & $0.14[-0.36-0.08]$ & $17.42(3.84)$ & $15.04(4.98)$ & $0.15[-0.48-0.19]$ & $-0.43[0.13-0.73]$ \\
\hline & Total & $16.24(4.77)$ & $16.29(4.67)$ & $16.60(4.65)$ & & & $16.89(3.84)$ & $16.16(4.45)$ & & \\
\hline \multirow{3}{*}{$\begin{array}{l}\text { BDI- } \\
\text { II }\end{array}$} & BPS & $8.08(6.42)$ & \multirow{3}{*}{--} & $4.87(3.93)$ & \multirow{3}{*}{--} & $0.49[0.20-0.77]^{*}$ & $4.37(5.89)$ & $4.19(5.33)$ & $0.57[0.24-0.89]^{*}$ & $0.59[0.24-0.94]^{*}$ \\
\hline & DA & $7.80(7.42)$ & & $5.97(6.11)$ & & $0.24[-0.01-0.49]$ & $3.71(4.70)$ & $4.60(5.44)$ & $0.54[0.22-0.86]^{*}$ & $0.42[0.10-0.75]^{*}$ \\
\hline & Total & $7.94(6.90)$ & & $5.43(5.16)$ & & & $4.03(5.29)$ & $4.40(5.35)$ & & \\
\hline
\end{tabular}

SPT-POS: Positive expectations (potential range 1-7); SPT-NEG: Negative Expectations (potential range 1-7); PA: Positive Affect (potential range 1-5); NA: Negative Affect (potential range 15); LOT-R: Life Orientation Test (potential range 0-24); BDI: Beck Depression Inventory (potential range 0-64); BPS: Best Possible Self; DA: Daily Activities

BDI-II was not included in the 15-days training

*Significant effect size, indicated by $95 \%$ Confidence Intervals. 
Click here to download line figure Figure 1.tif $\underline{\underline{ }}$

\begin{tabular}{|c|c|c|c|c|c|}
\hline PRE & $\begin{array}{l}\text { POST- } \\
\text { SESSION }\end{array}$ & \multirow{2}{*}{$\begin{array}{l}15 \text { DAYS - } \\
\text { TRAINING }\end{array}$} & \multirow{2}{*}{$\begin{array}{c}\text { POST- } \\
\text { TRAINING }\end{array}$} & \multirow{2}{*}{$\begin{array}{c}1^{\text {st }} \\
\text { FOLLOW-UP }\end{array}$} & \multirow{2}{*}{$\begin{array}{c}2^{\text {nd }} \\
\text { FOLLOW U }\end{array}$} \\
\hline & & & & & \\
\hline
\end{tabular}




\section{Enrollment}

Assessed for eligbility ( $n=89$ )

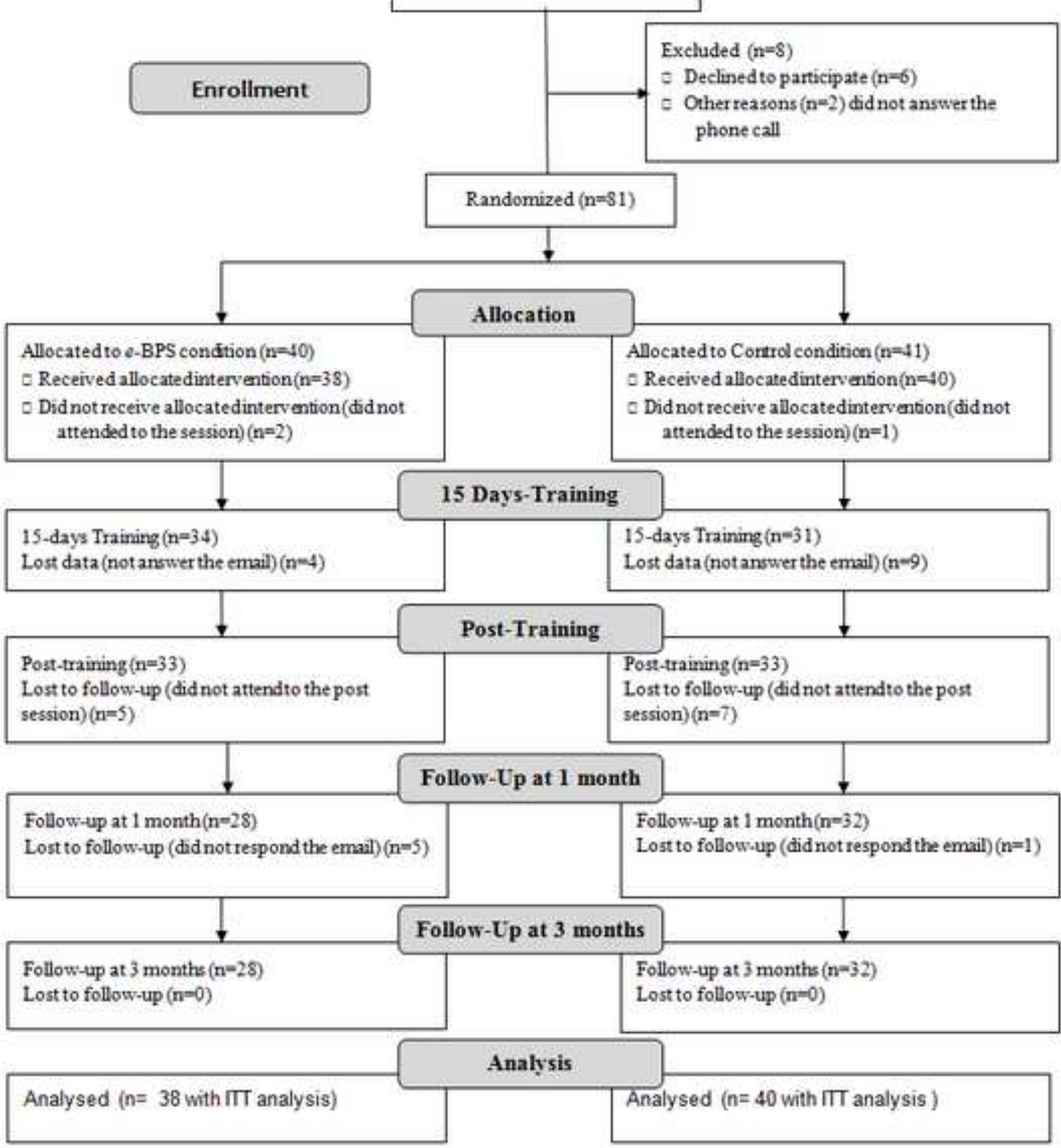




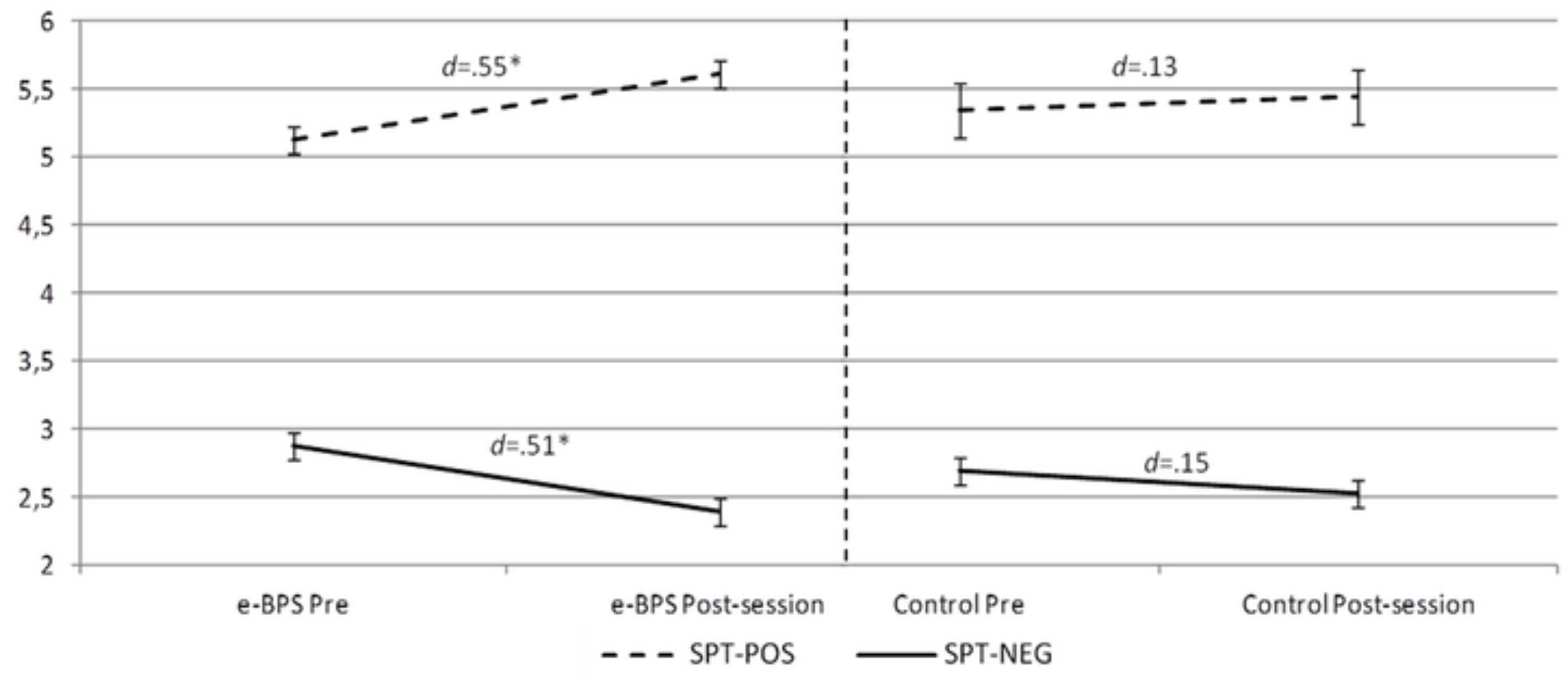




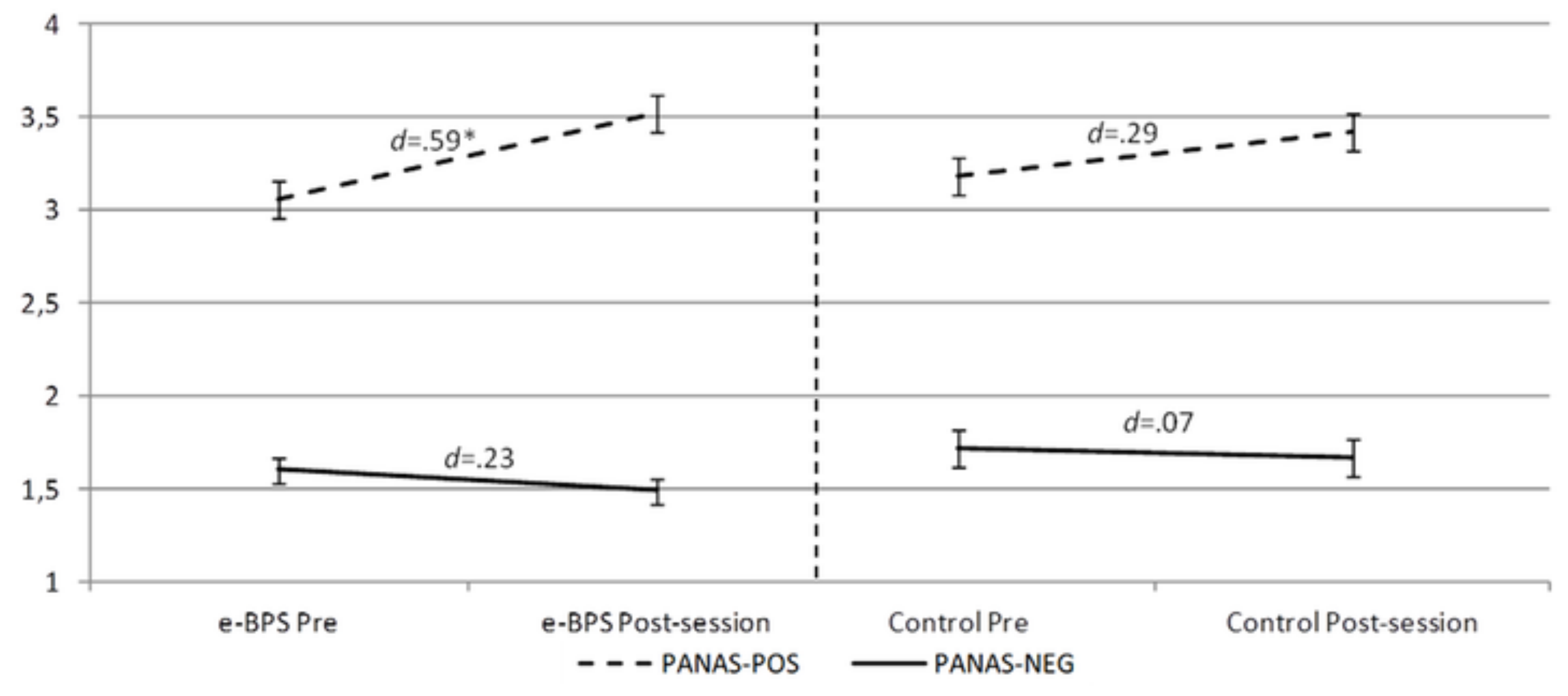




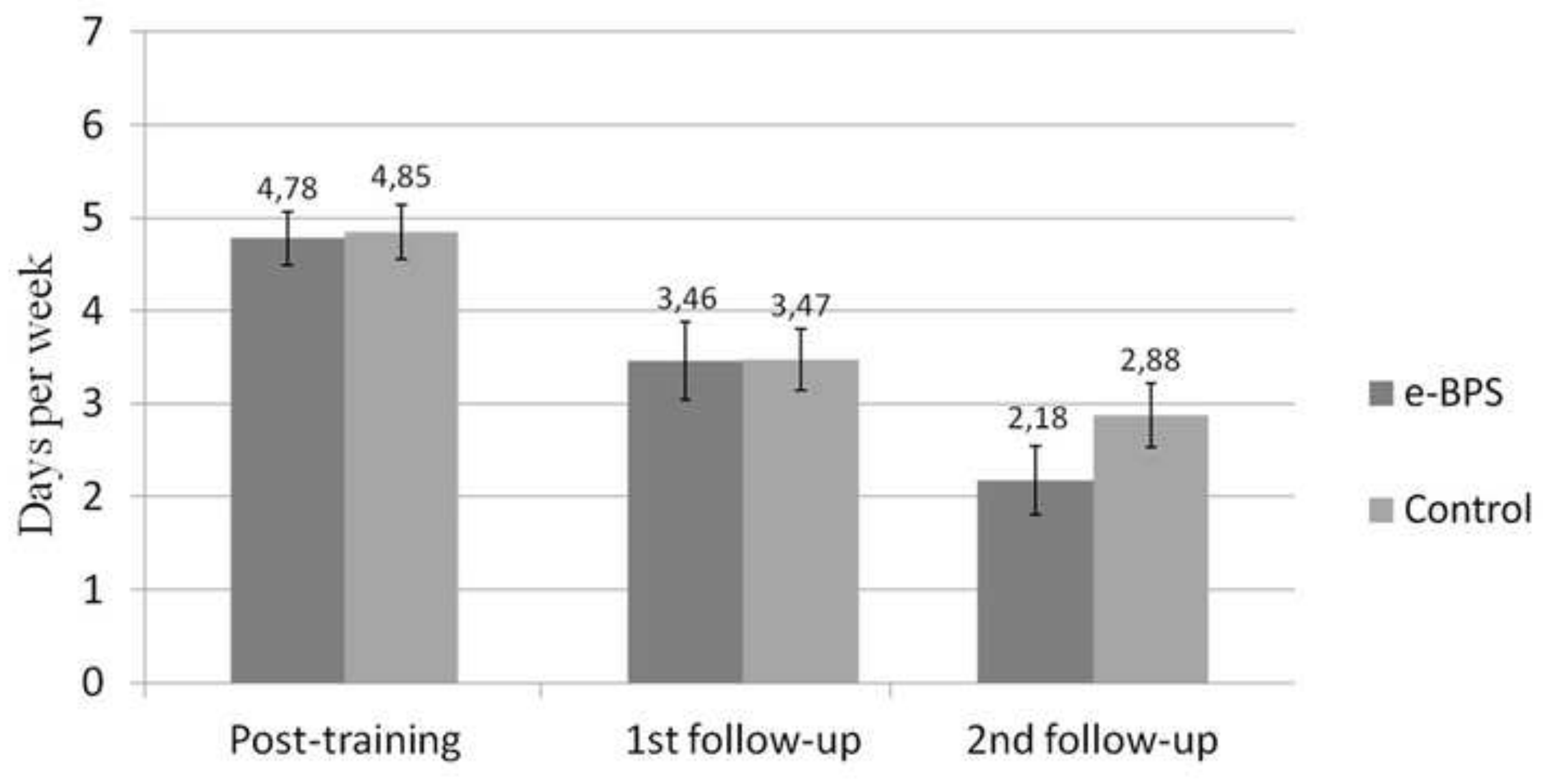

